\title{
Drug-induced senescence bystander proliferation in prostate cancer cells in vitro and in vivo
}

\author{
JA Ewald ${ }^{1,2}$, JA Desotelle', ${ }^{1,3}$ N Almassi' and DF Jarrard ${ }^{*, 1,2,3}$ \\ 'Department of Urology, University of Wisconsin School of Medicine and Public Health, Madison, WI 53792, USA; ${ }^{2}$ University of Wisconsin Paul P \\ Carbone Comprehensive Cancer Center, Madison, WI 53792, USA; ${ }^{3}$ University of Wisconsin Environmental and Molecular Toxicology Program, 600 \\ Highland Avenue, Madison, WI 53792, USA
}

Senescence is a distinct cellular response induced by DNA-damaging agents and other sublethal stressors and may provide novel benefits in cancer therapy. However, in an ageing model, senescent fibroblasts were found to stimulate the proliferation of cocultured cells. To address whether senescence induction in cancer cells using chemotherapy induces similar effects, we used GFP-labelled prostate cancer cell lines and monitored their proliferation in the presence of proliferating or doxorubicin-induced senescent cancer cells in vitro and in vivo. Here, we show that the presence of senescent cancer cells increased the proliferation of cocultured cells in vitro through paracrine signalling factors, but this proliferative effect was significantly less than that seen with senescent fibroblasts. In vivo, senescent cancer cells failed to increase the establishment, growth or proliferation of LNCaP and DUI 45 xenografts in nude mice. Senescent cells persisted as long as 5 weeks in tumours. Our results demonstrate that although drug-induced senescent cancer cells stimulate the proliferation of bystander cells in vitro, this does not significantly alter the growth of tumours in vivo. Coupled with clinical observations, these data suggest that the proliferative bystander effects of senescent cancer cells are negligible and support the further development of senescence induction as therapy.

British Journal of Cancer (2008) 98, I244-1249. doi:I0.1038/sj.bjc.6604288 www.bjcancer.com

Published online 18 March 2008

(c) 2008 Cancer Research UK

Keywords: senescence; bystander effect; prostate cancer; proliferation

Senescence is a physiological programme of terminal growth arrest occurring in both normal and immortalised cells in response to telomeric alterations, and also to sublethal stress and inappropriate oncogenic signalling. Senescent cells develop a characteristic phenotype, including an enlarged, flattened morphology, prominent nucleus, senescence-associated heterochromatin foci (SAHF), and senescence-associated $\beta$-galactosidase (SA $\beta$-gal) activity (Narita et al, 2003; Campisi, 2005; Lee et al, 2006). Cancer treatments, including radiation and chemotherapy, induce senescent characteristics in cells. Doxorubicin and cisplatin are more efficient in generating senescence in cell culture than ionising radiation, etoposide or the microtubule-targeting drugs docetaxel and vincristine (Chang et al, 1999). Heterogeneous $\mathrm{SA} \beta$-gal staining has been observed in sections of frozen human breast tumours after treatment with cyclophosphamide, doxorubicin and 5-fluorouracil (te Poele et al, 2002), and in lung tumours, after carboplatin and taxol (Roberson et al, 2005). Senescence develops at lower drug concentrations than apoptosis, potentially limiting treatment-related side effects (Schwarze et al, 2005).

Senescence may provide a number of unique therapeutic benefits. When senescence is induced by expressing p53 in a murine liver cancer model, an upregulation of inflammatory

*Correspondence: Dr DF Jarrard; E-mail: jarrard@surgery.wisc.edu Revised I 4 January 2008; accepted 31 January 2008; published online 18 March 2008 cytokines triggers an innate immune response that targets the tumour cells (Xue et al, 2007). Other studies have suggested senescence may function as an alternative mechanism of tumour inhibition. In mice bearing $\mathrm{E} \mu$-myc lymphomas, treated with cyclophosphamide, when apoptosis was blocked by Bcl-2 overexpression, senescence developed and these animals had improved survival over the apoptotic tumours (Schmitt et al, 2002). The recognition that a senescence programme may be reinduced in immortalised and tumorigenic cells by exposure to selected drugs presents a putative target for blocking cancer cell growth.

However, senescence induction may potentially promote tumour growth. Senescent cells express a variety of growth factors and secreted proteins that may stimulate as well as inhibit cell proliferation (Chang et al, 2002; Schwarze et al, 2002, 2005; Untergasser et al, 2002; Bavik et al, 2006). In contrast to apoptosis, a programme of cellular destruction, senescent cells persist and remain viable. SA $\beta$-gal activity in cells has been putatively identified in ageing tissues, including skin and benign prostatic hyperplasia specimens (Dimri et al, 1995; Choi et al, 2000). Consistent with the hypothesis that ageing induces a procarcinogenic environment, fibroblasts passaged to replicative senescence induce the proliferation of local bystander cells both in vitro and in xenografts (Krtolica et al, 2001; Bavik et al, 2006). To determine whether senescent cancer cells generate a bystander effect or not, we chemically induced senescence in prostate cancer cells using doxorubicin and examined their effect on a bystander cancer cells in vitro and in vivo. 


\section{MATERIALS AND METHODS}

\section{Cell lines and cell culture}

DU145 and LNCaP prostate cancer cell lines, and human primary fibroblasts, were cultured and senescence induced by treatment with $25 \mathrm{~nm}$ doxorubicin as described previously (Schwarze et al, 2005). Polyclonal green fluorescence protein $(\mathrm{GFP})^{(+)}$cell lines were generated by infecting DU145 and LNCaP cells with pLS-GFP virus and repeated sorting of $\mathrm{GFP}^{(+)}$cells. Resulting cell lines stably express GFP in $\sim 98$ and $\sim 80 \%$ of DU145- and LNCaPderived cell lines, respectively. $\mathrm{GFP}^{(+)}$cells in both lines were approximately $100 \times$ brighter than non-labelled cells, as measured by flow cytometry (data not shown).

\section{Cell-counting experiments}

For coculture experiments, 50000 DU145 or 200000 LNCaP $\mathrm{GFP}^{(+)}$tagged cells and equivalent proliferating or senescent untagged cells or 50000 senescent primary prostate fibroblasts were plated together in triplicate in $35-\mathrm{mm}$ wells containing growth medium. The following day, cells were washed twice in phosphate-buffered saline (PBS), given minimal medium $(50 \%$ $\mathrm{F} 12 / 50 \% \mathrm{DMEM}+$ penicillin/streptomycin) and returned to $37^{\circ} \mathrm{C}$, $5 \% \mathrm{CO}_{2}$. Cells were collected after 2 or 4 additional days in culture. Cell viability in counted samples was determined by annexinV binding (Invitrogen, Carlsbad, CA, USA) and by propidium iodide exclusion. Data were acquired from samples by flow cytometry and analysed using WinMDI v2.8 software (Joseph Trotter, Scripps Research Institute) to calculate the total number of viable $\mathrm{GFP}^{(+)}$ cells in each sample.

Counting experiments were repeated using threefold the number of proliferating or senescent cells (from 50000 to 150000 cells), or a decreased fraction of senescent cocultured cells (75 and $25 \%$ senescent $v s$ proliferating), incubated in minimal medium for 4 days and analysed as above.

\section{BrdU incorporation}

In cell-counting experiments (above), $20 \mathrm{~mm}$ BrdU was added to cell-culture medium, $30 \mathrm{~min}$ prior to trypsinisation, and $\mathrm{GFP}^{(+)}$ cells were recovered by fluorescence-activated cell sorting. Isolated cells were fixed in $100 \%$ ethanol and stored at $-20^{\circ} \mathrm{C}$. Subsequently, cells were rehydrated and stained for BrdU as described previously (Krtolica et al, 2001; Schwarze et al, 2003). BrdU incorporation of cells cocultured in transwells did not require cell sorting.

\section{Xenograft cocultures}

All animal protocols and studies were conducted in accordance with the guidelines of the Association for Assessment and Accreditation of Laboratory Animal Care International, and approval was obtained from the University of Wisconsin Institutional Animal Care and Use Committee. Male athymic nude mice were obtained from Harlan (Madison, WI, USA). Xenograft tumours were established as described previously (Passaniti et al, 1992a,b). DU145-GFP ${ }^{(+)}$and unlabelled proliferating or senescent DU145 cells $\left(0.5 \times 10^{6}\right.$, each) were injected into the mouse subinguinal fat pad and allowed to develop into xenograft tumours over 5 weeks time. Tumour dimensions were measured at 3, 4 and 5 weeks after injection using a caliper. BrdU was injected into these mice interperitoneally at a concentration of $70 \mathrm{mg} \mathrm{kg}^{-1}$ body weight (Christov et al, 1993), harvested $2 \mathrm{~h}$ later and dissociated into a single-cell suspension from which $\mathrm{GFP}^{(+)}$cells were isolated by fluorescence-activated cell sorting. These were fixed in ice-cold ethanol and stored at $-20^{\circ} \mathrm{C}$. BrdU incorporation was measured in recovered cells, as mentioned above.
LNCaP xenografts were established by injecting $1 \times 10^{6} \mathrm{LNCaP}$ cells alone, with 50\% Matrigel (BD Biosciences, San Jose, CA, USA) or with an equal number of senescent LNCaP cells as described (Passaniti et al, 1992a, b), and cells were measured as mentioned above. Additionally, xenografts were established using $0.5 \times 10^{6}$ DU145 cells with or without addition of equal number of senescent GFP $^{(+)}$-DU145 cells. Tumours were measured as mentioned above, harvested at 3 and 5 weeks and samples were frozen in OCT for sectioning.

\section{Immunofluorescence staining and microscopy}

Ten micrometre sections of xenografts were fixed in PBS $+4 \%$ paraformaldehyde/0.2\% Triton X-100/10 mM NaF/1 mM $\mathrm{Na}^{2} \mathrm{VO}_{4}$ and washed in PBS $+0.2 \%$ Triton X-100/10 mm NaF/1 mM Na3VO (wash buffer) before incubation in blocking buffer (wash buffer + $10 \%$ fetal bovine serum $+1 \%$ bovine serum albumin) for $1 \mathrm{~h}$ at room temperature. Sections were washed in blocking buffer and incubated with $1 \mu \mathrm{g} \mathrm{ml}^{-1}$ anti-IGF2 as a cellular counterstain ( $1: 200$ dilution; Santa Cruz Biotechnology, Inc., Santa Cruz, CA, USA; no. sc-5622) overnight at $4^{\circ} \mathrm{C}$. Sections were again washed, incubated for $1 \mathrm{~h}$ with $200 \mathrm{ng} \mathrm{ml}^{-1}$ (1:1000 dilution) anti-rabbitAlexa $594+10 \mathrm{ng} \mathrm{ml}^{-1}$ Hoechst 33342 (Invitrogen), washed and mounted using ProLong Gold (Invitrogen). Images were captured using an Olympus microscope with mercury lamp, appropriate filters and spot digital camera and imaging software (Diagnostic Instruments Inc., Sterling Heights, MI, USA). Images were merged and visualised using NIH ImageJ (http://rsb.info.nih.gov/ij/).

\section{Statistical methods}

Data were analysed, standard deviation and standard error were calculated, and Student's $t$-tests were performed using Microsoft Excel. Error bars in all figures represent one standard deviation in the data.

\section{RESULTS}

We generated stable GFP-expressing lines of the hormonerefractory DU145 (p53-inactive) and the androgen-dependent LNCaP (expressing functional p53) prostate cancer cell lines. To monitor the bystander effect of chemically induced senescent cancer cells, $\mathrm{GFP}^{(+)}$cells were cocultured with proliferating or senescent unlabelled cancer cells, collected and analysed by flow cytometry. Both DU145 and LNCaP cells treated with low-dose ( $25 \mathrm{~nm}$ ) doxorubicin for 3 days develop a senescent phenotype, increased SA $\beta$-gal staining (Figure 1A), and express previously described senescence marker genes (Schwarze et al, 2005).

Initially, DU145-GFP ${ }^{(+)}$or LNCaP-GFP ${ }^{(+)}$cells were plated with equal numbers of proliferating or doxorubicin-induced senescent untagged cells and cultured in a minimal serum-free medium for 2 and 4 days. GFP ${ }^{(+)}$cells cocultured with senescent cells were similar in number to those cocultured with proliferating cells at 2 days (Figure 1B). However, after 4 days, a significant increase in DU145 (1.46 fold; $P<0.0001$ ) and LNCaP (1.51 fold; $P=0.022$ ) cells was observed when cocultured with senescent cells. Apoptosis of $\mathrm{GFP}^{(+)}$cells, measured by annexin-V binding and propidium iodide exclusion at each time point, was not significantly affected by the presence of senescent cells $(<1 \%$ in each sample), suggesting that these observed differences were not due to effects on cell survival. Proliferation, measured by BrdU incorporation, was also increased at day $4(16-21 \% ; P=0.003)$ in $\mathrm{GFP}^{(+)}$DU145 cells, exposed to senescent cells (Figure 1C). When DU145 and LNCaP cells were cocultured in $0.4 \mathrm{~m}$ transwell inserts, preventing contact between the two populations but allowing exposure to common media, BrdU incorporation was similarly increased (20-24\%; $P<0.0001$ and $P<0.05$, respectively). Given 
A

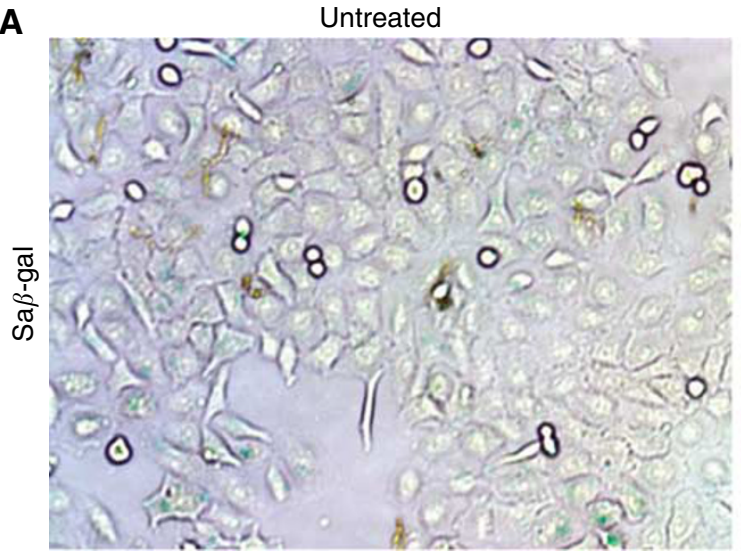

B

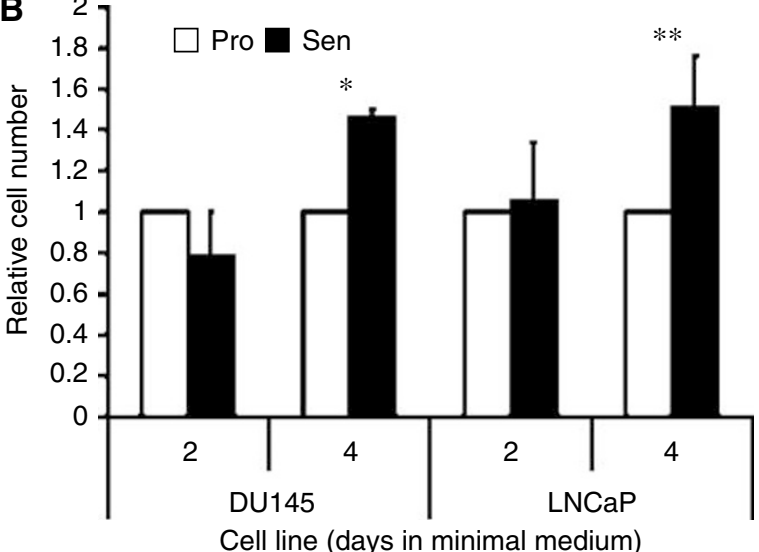

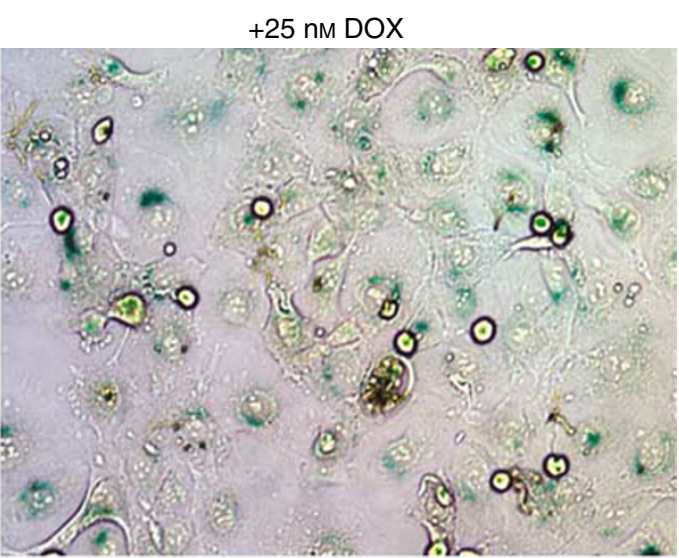

C

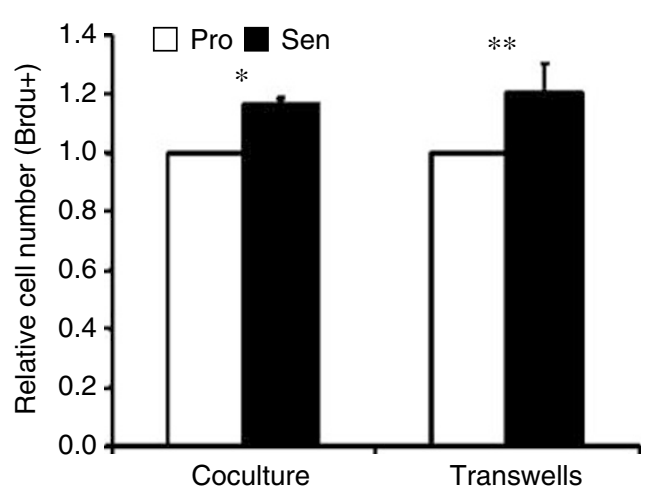

Figure I Proliferative bystander effect of drug-induced senescent prostate cancer cells in vitro. (A) Bright-field images of DUI45 cells cultured on cover slips \pm 25 nM doxorubicin (DOX) for 3 days, fixed and stained for SA $\beta$-gal activity $(400 \times)$. (B) Number of proliferating DUI45-GFP $(+)$ or LNCaP-GFP $(+)$ cells after coculture with proliferating or senescent non-tagged cancer cells measured by flow cytometry. Replicate results were averaged from four independent experiments. These results represent the average fold increase of cell numbers in senescent cocultures relative to proliferative cell data. Error bars represent standard error ( $* P<0.0001$; ** $P=0.022$ ). (C) BrdU + incorporation in cells after direct coculture (left) and in transwells (right) after 30 min incubation with 20 um BrdU. The results of three independent experiments were averaged and the numbers of cells from senescent cocultures were normalised to that of proliferating cocultures. Error bars represent standard error $(* P=0.003, * * P<0.000 \mathrm{I})$.

the similar magnitude of this proliferative response to the mixing experiments performed on single plates suggested the majority of the growth stimulation observed was induced by secreted soluble factors.

Increasing the numbers of cocultured proliferating and senescent cells threefold in both DU145 and LNCaP cells (150000 cells) sustained this proliferative response (1.4-fold; in both DU145 and LNCaP cells $P=0.03$ and $P=0.003$, respectively; data not shown) demonstrating that this effect was not an artifact of media depletion. Decreasing the fraction of cocultured senescent cells to 38 and $12 \%$ of the total cell population (decrease of 25 and $75 \%$ in the unlabelled senescent cells) did not induce proliferation (data not shown). These results demonstrate that a proliferative bystander effect can be stimulated in vitro by chemically induced senescent prostate cancer cells through paracrine signalling.

Previously published data have demonstrated a significant proliferative response of bystander cells to senescent fibroblast lines (Krtolica et al, 2001; Bavik et al, 2006). Therefore, we compared the proliferative bystander response of senescent DU145 cells to three replicatively senescent prostate fibroblast lines generated through prolonged passage in cell culture (Figure 2A). Senescent fibroblasts demonstrated SA- $\beta$ gal staining and senescent morphology. After 4 days in coculture, the increase in the number of prostate cancer cells exposed to senescent fibroblasts was twice that seen with senescent cancer cells (60 vs $30 \%$, respectively; $P<0.01$ ). We then confirmed the induction ( $>2$ fold) of a number of growth-promoting paracrine factors in our chemically induced senescent DU145 and LNCaP cells (Figure 2B) using qPCR. No increase in expression of these genes (IGF2, BRAK, FGF11 and Wnt5a) was seen in the senescent fibroblast lines. Comparing growth-promoting gene expression data from a number of studies involving fibroblasts, epithelial cells and cancer cells (Schwarze et al, 2005; Bavik et al, 2006) reveals little overlap when fibroblasts are compared to other cell lines (Figure 2B). In sum, our data show that senescent fibroblasts induce the proliferation of bystander cells in vitro significantly more than senescent prostate cancer cells.

Next, we investigated whether senescent cancer cells promote the growth of non-senescent cancer cells in nude mouse tumour xenograft models or not. LNCaP prostate cancer xenografts require additional growth factors, provided by Matrigel $^{\mathrm{TM}}$, to establish viable tumours and proliferate (Passaniti et al, 1992a,b). To determine if senescence has a similarly permissive effect on xenograft tumour establishment, mice were injected with $1 \times 10^{6}$ LNCaP cells either alone, with $50 \%$ Matrigel or with $1 \times 10^{6}$ senescent LNCaP cells ( $n=5$ in each group). Six weeks after injection, LNCaP cells coinjected with Matrigel developed into viable tumours in all five animals. In contrast, tumours did not develop under the other conditions (0/10 mice). This demonstrates that chemically induced senescent LNCaP cells do not promote tumour establishment and/or growth of this cell line. 


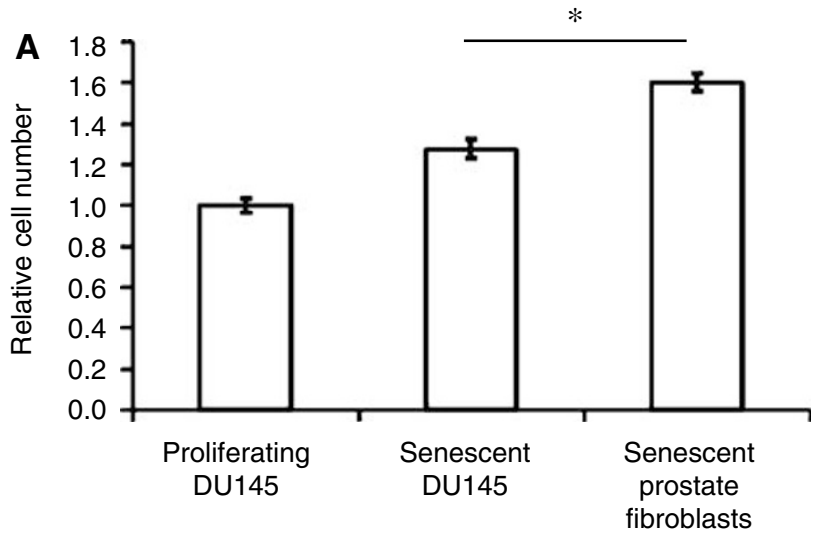

B

\begin{tabular}{|c|c|}
\hline $\begin{array}{c}\text { Schwarze } \\
\text { Senescent } \\
\text { prostate } \\
\text { cancer cells }\end{array}$ & $\begin{array}{c}\text { Bavik } \\
\text { Senescent } \\
\text { prostate } \\
\text { fibroblasts }\end{array}$ \\
\hline Igf2* $^{*}$ & Amphiregulin \\
Fgf11* $^{*}$ & CXCL1 \\
Wnt5a* & CXCL13 \\
BRAK* & CCL20 \\
MFAP2 & CCL2 \\
& Cytokine-like \\
& Protein C17 \\
& FGF7 \\
& HGF \\
& IL-8 \\
\hline
\end{tabular}

Figure 2 Bystander proliferation induced to a greater extent by replicatively senescent prostate fibroblasts than senescent prostate cancer cells. (A) Number of proliferating DUI45-GFP ${ }^{(+)}$cells cocultured with proliferating or senescent DUI45 cells or three independent primary prostate fibroblast cell lines after passage to replicative senescence. Data from all three senescent fibroblast lines were averaged. Results are expressed relative to proliferating coculture data. Error bars represent standard error $(* P<0.0 I)$. Results are representative of two experiments. (B) Expression of secreted growth factor genes reported in chemically induced senescent prostate cancer cells and senescent fibroblast ('Schwarze et al, 2005 Neoplasia; ${ }^{2}$ Bavik et al, 2006. Canc. Res. *Increased gene expression confirmed in senescent cancer cells by quantitative RT-PCR in the present study).

Next, we examined the effect of senescent cells on tumour growth in DU145 xenografts using two different approaches. First, we coinjected $0.5 \times 10^{6}$ DU145-GFP ${ }^{(+)}$proliferating cells with an equal number of unlabelled proliferating or senescent DU145 cells $\left(1 \times 10^{6}\right.$ total $)$ to model the effects of treatment-induced senescence in $50 \%$ of tumour cells. Tumours were palpable in both groups after 2 weeks and tumour dimensions were measured 3, 4 and 5 weeks after injection. The average volume of tumours established with or without senescent cells was calculated for each time point. Reflecting the greater number of proliferating cells initially injected, xenografts containing only proliferating cells grew significantly larger than those containing senescent cells after 5 weeks $(P<0.001)$ (Figure $3 \mathrm{~A}$, left). However, the average exponential rate of tumour growth was not significantly affected by the presence of senescent cells, illustrated by calculating the natural $\log (\ln )$ of the average tumour volume over time (Figure 3A, right). Control animals, in which only senescent cells were injected, did not develop palpable tumours through the course of these experiments. Mice were injected with $70 \mathrm{mg} \mathrm{kg}^{-1}$ body weight BrdU $2 \mathrm{~h}$ prior to tumour harvest to measure proliferation in sorted $\mathrm{GFP}^{(+)}$tumour cells (Christov et al, 1993). Cells from DU145 tumours established with or without senescent cells and collected after 5 weeks contain similar fractions of proliferating cells as measured by BrdU uptake and DNA profiling (data not shown). As a second approach, we repeated this experiment by beginning with equivalent numbers $\left(0.5 \times 10^{6}\right)$ of proliferating DU145 cells and determining the effect of adding additional $\left(0.5 \times 10^{6}\right)$ senescent cells. Again, the presence of senescent cells did not increase average tumour size or the rate of tumour growth (Figure 3B left, right).

Using senescent GFP ${ }^{(+)}$-DU145 cells in this second approach allowed us to determine whether senescent cells persisted through the growth of these tumours or not. $\mathrm{GFP}^{(+)}$senescent cells were detected in xenograft tumours harvested 3 and 5 weeks after injection. However, at these time points, senescent cells were found infrequently (1-4 cells per section; mean $1 \mathrm{hpf}$; Figure $3 \mathrm{C})$. SA $\beta$-gal analysis of tumour sections demonstrated infrequently stained cells, confirming these findings (data not shown). These results demonstrate that non-proliferating senescent cells become diluted during xenograft growth, yet persist even 5 weeks after injection. Therefore, the presence of chemically senescent cancer cells does not increase the rate of xenograft tumour establishment or growth in vivo.

\section{DISCUSSION}

Significant interest has been generated regarding the role of senescence as a tumour suppressor and the clinical ramifications of its reactivation in cancer (Schmitt et al, 2002; Petti et al, 2006; Xue et al, 2007). Potential exists for development of therapeutic compounds that specifically induce senescence in cancer cells (Roninson, 2003). However, concerns have been raised regarding the promoting effect of senescent cancer cells on the tumour microenvironment, similar to that seen with senescent fibroblasts (Kahlem et al, 2004). Our results demonstrate that a limited proliferative response occurs in vitro with chemically induced senescent cells when compared to senescent fibroblasts (Figure 2A). However, this bystander effect does not affect xenograft tumour establishment or the growth of non-senescent bystander tumour cells in vivo (Figure 3 ).

Using multiple cell types and combinations, senescent cells did not impact in vivo tumour growth or proliferation. When xenografts were established using proliferating cells with and without senescent cells, tumours were consistently smaller in the presence of senescent cells (Figure 3B). We acknowledge that a transient increase in proliferation may be induced prior to the development of a palpable tumour, but clearly, the long-term impact on tumour size was not significant. Technically similar mixing experiments in immune-deficient mice have been performed using senescent fibroblasts and a stimulatory effect was easily demonstrated using multiple immortalised and tumorigenic cell lines (Krtolica et al, 2001; Parrinello et al, 2005; Bavik et al, 2006). In vivo, these studies utilised equivalent numbers of proliferating and senescent cells similar to our methods. Our data clearly show the lack of a stimulatory response when senescent cancer cells are mixed with proliferating cancer cells in tumours. Furthermore, with current chemotherapy regimens, senescent cells appear at a much lower frequency $(<20 \%)$ than those tested in our experiments (te Poele et al, 2002; Roberson et al, 2005).

As part of our study, we contrasted, in vitro, the bystander effect of senescent fibroblasts to that seen with chemically induced senescent cancer cells. Using our quantitative and reproducible model, the in vitro proliferative effect of senescent cancer cells was noted to be $40-50 \%$ of that seen with senescent fibroblasts. Our 

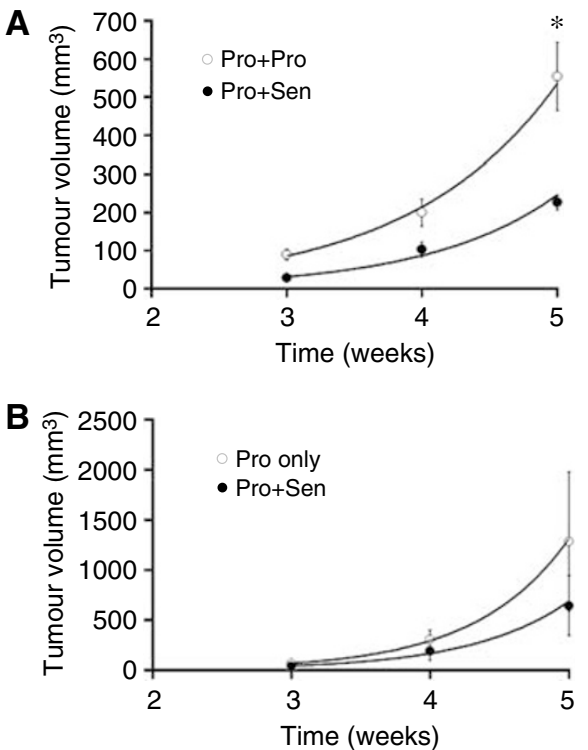
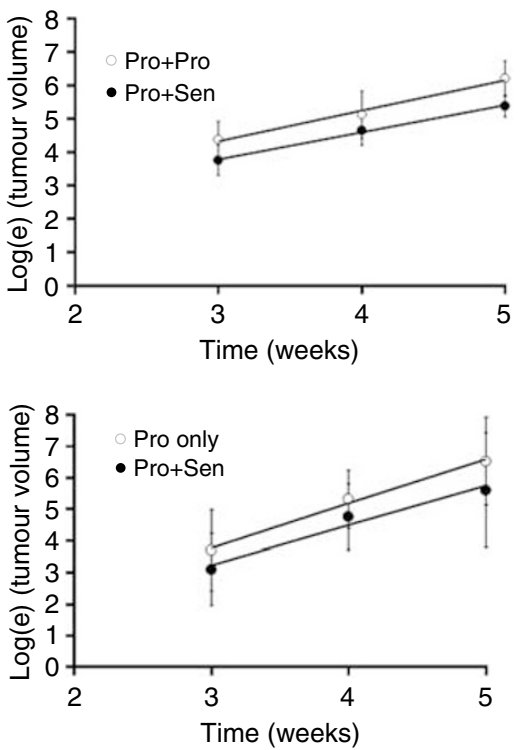

C

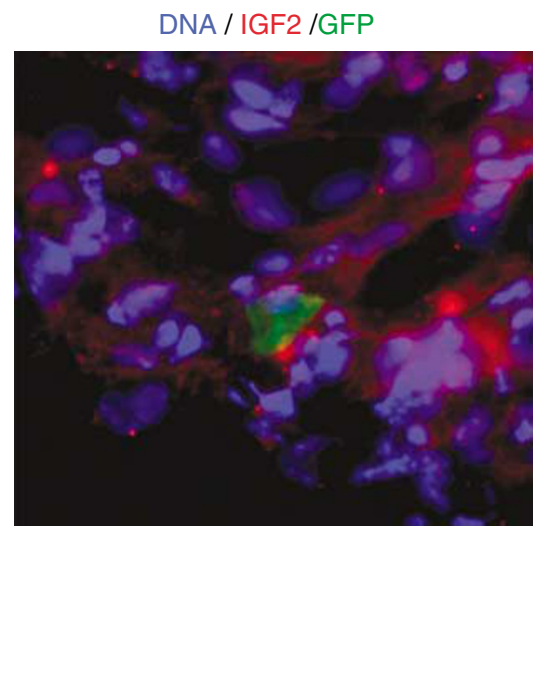

Figure 3 Xenograft tumour growth is not promoted by senescent DUI45 cells. (A) Average size (left) and natural log of tumour size (right) of prostate xenograft tumours established using DUI45-GFP( $\left.{ }^{+}\right)$cells $\left(0.5 \times 10^{6}\right)$ mixed with an equal number proliferating (Pro + Pro) or senescent $($ Pro + Sen) cells and measured for 5 weeks. Error bars represent standard error $(* P<0.001)$. Fit equations: (left) (Pro + Pro): $y=5.491 e^{0.913 x}\left(R^{2}=0.996\right) ;($ Pro + Sen): $y=1.362 e^{1.039 x}\left(R^{2}=0.981\right)$; (right) (Pro + Pro): $y=0.917 x+1.565\left(R^{2}=0.989\right) ;\left(\right.$ Pro + Sen) $: y=0.813 x+1.340\left(R^{2}=0.997\right)$. (B) Average size (left) and natural log of tumour size (right) of prostate xenograft tumours established using DUI $45\left(0.5 \times 10^{6}\right)$ cells alone (Pro only) or with an equal number of additional senescent GFP( + -DUI 45 cells (Pro + Sen). Error bars represent standard error. Fit equations: (left)(Pro only): $y=0.739 e^{1.491 x}\left(R^{2}=0.999\right)$; (Pro + Sen): $y=0.576 \mathrm{e}^{1.417 x}\left(R^{2}=0.994\right) ;\left(\right.$ right)(Pro only): $y=1.41 x-0.458\left(R^{2}=0.994\right) ;\left(\right.$ Pro + Sen): $y=1.254 x-0.527\left(R^{2}=0.966\right)$. (C) Xenograft tumour section containing a senescent GFP ${ }^{(+)}$-DUI 45 cell. Hoechst 33342 (blue) was used to stain nuclei and anti-IGF2 (red) was used to stain cytoplasm $(400 \times)$. This image is representative of sections from 10 xenograft tumours containing I-4 GFP ${ }^{(+)}$cells per section (mean: I hpf).

quantitative PCR analysis confirmed the results of studies that show significant variation between growth-promoting genes expressed by senescent epithelial cells, fibroblasts and cancer cells (Chang et al, 2002; Schwarze et al, 2002, 2005; Untergasser et al, 2002; Zhang et al, 2003; Bavik et al, 2006). The finding that gene expression perturbations during senescence differ greatly between fibroblasts and epithelial cells, but show physical clustering on DNA, has been thought to reflect the altered chromatin structure seen during senescence (Zhang et al, 2003). These changes are likely to be even more marked in cancer cells containing deletions, duplications and distorted nuclear structure.

In vivo, the expression of secreted extracellular matrix, growth factors and surface receptor proteins differs markedly from cells cultured in vitro (Gieseg et al, 2004). This disparity in the tumour microenvironment may contribute to the lack of induction of proliferation in response to senescent cells in vivo. As an example, IGF2 protein expression is clearly elevated in senescent cancer cells in vitro, but the expression of IGF2 protein does not quantitatively differ in vivo, when senescent and proliferating cells are compared (data not shown). A unique aspect of our study is the demonstration of a persistence of senescent cells in tumours as long as 5 weeks after injection. They represent a small population at this time point, less than $1 \%$, due to expansion of the proliferating population, which doubles in roughly $48 \mathrm{~h}$ (Passaniti et al, 1992a,b). Senescent cells have been noted in the skin of elderly individuals (Dimri et al, 1995) and in melanocytic naevi (Michaloglou et al, 2005). Our data in a xenograft model would support the persistence of these cells in various organs.

Placing senescence induction in the context of cancer treatment, our results suggest that the specific induction of senescence in prostate tumour cells would not promote tumour growth. Accumulating data suggest that senescent cells may occur in vivo after the treatment of tumours with chemotherapy, in approximately $40 \%$ of breast tumours after treatment using a CAF regimen (te Poele et al, 2002). Other observations support that senescence in vivo is a beneficial phenotype by inducing a cellular immune response (Petti et al, 2006; Xue et al, 2007) and demonstrating a survival advantage when compared to solely apoptotic responses (Schmitt et al, 2002). Recently, senescent cells were identified in human melanocytic nevi, a benign, stable skin lesion, supporting its function as a long-term tumour-suppressive mechanism (Michaloglou et al, 2005). In this case, there are no apparent signs of enhanced bystander proliferation or increased local carcinogenesis. Staining for senescent cells has also been identified in benign prostatic hyperplasia tissues, a common benign entity not associated with cancer (Choi et al, 2000). In conclusion, our data demonstrate that the presence of chemically senescent prostate cancer cells does not significantly enhance the growth of tumour xenografts, providing further rationale for the development of anticancer strategies that efficiently induce senescence in advanced cancers.

\section{ACKNOWLEDGEMENTS}

We acknowledge the helpful flow cytometry expertise of Kathy Schell, Colleen Urben and Joel Puchalski; Dr Glenn Leverson and Dr Alejandro Munoz of the Department of Surgery (University of Wisconsin Hospital) for help with statistical analysis and data interpretation.

This work was supported by the National Institutes of Health (R01CA97131) and the University of Wisconsin, George M O'Brien Urology Research Center (1P50DK065303) and the John Livesey endowment. JE is supported through the NIH training Grant T32 CA009681 to the University of Wisconsin McArdle Laboratory Cancer Biology Training Program. No financial relationship between any of the authors and the subject matter. 


\section{REFERENCES}

Bavik C, Coleman I, Dean JP, Knudsen B, Plymate S, Nelson PS (2006) The gene expression program of prostate fibroblast senescence modulates neoplastic epithelial cell proliferation through paracrine mechanisms. Cancer Res 66: 794-802

Campisi J (2005) Senescent cells, tumor suppression, and organismal aging: good citizens, bad neighbors. Cell 120: $513-522$

Chang BD, Broude EV, Dokmanovic M, Zhu H, Ruth A, Xuan Y, Kandel ES, Lausch E, Christov K, Roninson IB (1999) A senescence-like phenotype distinguishes tumor cells that undergo terminal proliferation arrest after exposure to anticancer agents. Cancer Res 59: $3761-3767$

Chang BD, Swift ME, Shen M, Fang J, Broude EV, Roninson IB (2002) Molecular determinants of terminal growth arrest induced in tumor cells by a chemotherapeutic agent. Proc Natl Acad Sci USA 99: 389-394

Choi J, Shendrik I, Peacocke M, Peehl D, Buttyan R, Ikeguchi EF, Katz AE, Benson MC (2000) Expression of senescence-associated beta-galactosidase in enlarged prostates from men with benign prostatic hyperplasia. Urology 56: $160-166$

Christov K, Swanson SM, Guzman RC, Thordarson G, Jin E, Talamantes F, Nandi S (1993) Kinetics of mammary epithelial cell proliferation in pituitary isografted BALB/c mice. Carcinogenesis 14: 2019-2025

Dimri GP, Lee X, Basile G, Acosta M, Scott G, Roskelley C, Medrano EE, Linskens M, Rubelj I, Pereira-Smith O, Peacocke M, Campisi J (1995) A biomarker that identifies senescent human cells in culture and in aging skin in vivo. Proc Natl Acad Sci USA 92: 9363-9367

Gieseg MA, Man MZ, Gorski NA, Madore SJ, Kaldjian EP, Leopold WR (2004) The influence of tumor size and environment on gene expression in commonly used human tumor lines. BMC Cancer 4: 35

Kahlem P, Dorken B, Schmitt CA (2004) Cellular senescence in cancer treatment: friend or foe? J Clin Invest 113: 169-174

Krtolica A, Parrinello S, Lockett S, Desprez PY, Campisi J (2001) Senescent fibroblasts promote epithelial cell growth and tumorigenesis: a link between cancer and aging. Proc Natl Acad Sci USA 98: 12072-12077

Lee BY, Han JA, Im JS, Morrone A, Johung K, Goodwin EC, Kleijer WJ, DiMaio D, Hwang ES (2006) Senescence-associated beta-galactosidase is lysosomal beta-galactosidase. Aging Cell 5: 187-195

Michaloglou C, Vredeveld LC, Soengas MS, Denoyelle C, Kuilman T, van der Horst CM, Majoor DM, Shay JW, Mooi WJ, Peeper DS (2005) BRAFE600-associated senescence-like cell cycle arrest of human naevi. Nature 436: $720-724$

Narita M, Nunez S, Heard E, Narita M, Lin AW, Hearn SA, Spector DL, Hannon GJ, Lowe SW (2003) Rb-mediated heterochromatin formation and silencing of E2F target genes during cellular senescence. Cell 113: $703-716$
Parrinello S, Coppe JP, Krtolica A, Campisi J (2005) Stromal-epithelial interactions in aging and cancer: senescent fibroblasts alter epithelial cell differentiation. J Cell Sci 118: $485-496$

Passaniti A, Adler SH, Martin GR (1992a) New models to define factors determining the growth and spread of human prostate cancer. Exp Gerontol 27: $559-566$

Passaniti A, Isaacs JT, Haney JA, Adler SW, Cujdik TJ, Long PV, Kleinman HK (1992b) Stimulation of human prostatic carcinoma tumor growth in athymic mice and control of migration in culture by extracellular matrix. Int J Cancer 51: 318-324

Petti C, Molla A, Vegetti C, Ferrone S, Anichini A, Sensi M (2006) Coexpression of NRASQ61R and BRAFV600E in human melanoma cells activates senescence and increases susceptibility to cell-mediated cytotoxicity. Cancer Res 66: 6503-6511

Roberson RS, Kussick SJ, Vallieres E, Chen SY, Wu DY (2005) Escape from therapy-induced accelerated cellular senescence in p53-null lung cancer cells and in human lung cancers. Cancer Res 65: 2795-2803

Roninson IB (2003) Tumor cell senescence in cancer treatment. Cancer Res 63: $2705-2715$

Schmitt CA, Fridman JS, Yang M, Lee S, Baranov E, Hoffman RM, Lowe SW (2002) A senescence program controlled by p53 and p16INK4a contributes to the outcome of cancer therapy. Cell 109: $335-346$

Schwarze SR, DePrimo SE, Grabert LM, Fu VX, Brooks JD, Jarrard DF (2002) Novel pathways associated with bypassing cellular senescence in human prostate epithelial cells. J Biol Chem 277: 14877-14883

Schwarze SR, Fu VX, Desotelle JA, Kenowski ML, Jarrard DF (2005) The identification of senescence-specific genes during the induction of senescence in prostate cancer cells. Neoplasia 7: 816-823

te Poele RH, Okorokov AL, Jardine L, Cummings J, Joel SP (2002) DNA damage is able to induce senescence in tumor cells in vitro and in vivo. Cancer Res 62: $1876-1883$

Untergasser G, Koch HB, Menssen A, Hermeking H (2002) Characterization of epithelial senescence by serial analysis of gene expression: identification of genes potentially involved in prostate cancer. Cancer Res 62: $6255-6262$

Xue W, Zender L, Miething C, Dickins RA, Hernando E, Krizhanovsky V, Cordon-Cardo C, Lowe SW (2007) Senescence and tumour clearance is triggered by p53 restoration in murine liver carcinomas. Nature 445: $656-660$

Zhang H, Pan KH, Cohen SN (2003) Senescence-specific gene expression fingerprints reveal cell-type-dependent physical clustering of upregulated chromosomal loci. Proc Natl Acad Sci USA 100: 3251 - 3256 